\title{
Tras la crisis de la Cultura Kodak: un análisis de la funcionalidad de la fotografía personal en la web 2.0
}

\author{
Enric Mira PASTOR \\ Universidad de Alicante \\ enric.mira@ua.es
}

\section{Resumen:}

La conectividad y la interacción social surgidas con las plataformas on line para compartir fotografías han alterado por completo la funcionalidad de las imágenes con la deriva hacia una serie de fenómenos como el exceso de imágenes, la amateurización de la prácticas fotográficas y la mediación tecnológica de la memoria.

Palabras clave: Cultura Kodak; exceso de imágenes; ubicuidad; amateurización; conectividad; memoria.

\section{After the Kodak Culture crisis: an analysis of the functionality of the personal photography in the web 2.0.}

\begin{abstract}
:
Connectivity and social interaction that emerged with on line platforms for sharing photographs have altered completely the functionality of images, while appears a series of phenomena such as the excess of images, the amateurization of the photographic practices and the technological mediation of memory.
\end{abstract}

Key Words: Kodak Culture; excess of images; ubiquity; amateurization; connectivity; memory.

\section{Referencia normalizada:}

Mira Pastor, E. (2014): Tras la crisis de la cultura kodak: un análisis de la funcionalidad de la fotografía personal en la web. Historia y Comunicación Social. Vol. 19. Núm. Especial Febrero. Págs. 747-758.

Sumario: 1. Introducción. 2. Exceso de imágenes y amateurización de las prácticas fotográficas. 3. Conectividad y memoria en red. 4. Conclusiones abiertas. 5. Bibliografía.

\section{Introducción}

A finales del siglo XIX, gracias al lanzamiento por parte de Eastman Kodak de la primera cámara fotográfica cargada con película lista para apuntar y disparar, la fotografía se convertía en tecnología de consumo, adquiriendo una nueva dimensión social en un entorno que iba a estar marcado por una serie de cambios tecnológicos 
y sociales como fueron la aparición del automóvil o el desarrollo del turismo. La fotografía era un producto tecnológico simple y fiable, y a la postre deseable, al que podían acceder amplias capas de la población, especialmente las familias de clase media, como instrumento para captar y guardar aquellos acontecimientos domésticos y de ocio más significativos (Slater, 1991) que la firma de Rochester publicitaba como "momentos Kodak" (Munir y Phillips, 2013). De este modo, la fotografía personal o amateur quedaba vinculada desde su mismos comienzos al domino doméstico como una forma privada de entretenimiento y un modo de representar a la familia en sus diversas actividades de cara a sus propios miembros y allegados. En esta relación entre lo doméstico, el consumo y el ocio se forjó el núcleo de la cultura fotográfica amateur (Slater, 1997) que Richard Chalfen etiquetó como Cultura Kodak (1987). ${ }^{1}$ Una vinculación entre la marca comercial y la fotografía popular que vendría a evidenciar no sólo la posición de liderazgo ocupada por sus productos en la expansión de la fotografía fotoquímica a lo largo de los años sino, sobre todo, a identificar un paradigma de lo fotográfico como práctica social, fundamentalmente ligada al entorno privado de lo doméstico, que comprende un conjunto específico de usos, normas y fines.

El fenómeno del consumo masivo de las tecnologías de la imagen se fue desarrollando a lo largo del siglo XX con la renovación constante del mercado a través de innovaciones técnicas que, bajo la lógica de la simplicidad en el uso implantada por Eastman Kodak, atendían a una demanda de usuarios en crecimiento. La fotografía en color, las polaroids de revelado instantáneo, las cámaras de cine de película de $8 \mathrm{~mm}$ o las de vídeo doméstico de cinta magnética son claros ejemplos. En los comienzos del siglo XXI asistimos a una coyuntura inédita en la función social de la fotografía por la conjugación de dos factores. De un lado, la expansión de smartphones con acceso a internet y provistos de cámara fotográfica ${ }^{2}$ que convierten la toma de imágenes - fijas o en movimiento- en un hecho radicalmente cotidiano y, del otro, la aparición en la web 2.0 de plataformas de social media como Facebook, Flickr o Instagram articuladas sobre la capacidad del usuario para generar contenidos fotográficos para la red e interactuar con ellos. Como nunca había ocurrido antes, capturar, editar y compartir imágenes fotográficas conforman momentos integrados de un mismo proceso de comunicación permanentemente accesible al usuario, convirtiendo a la fotografía en un elemento omnipresente en la vida diaria con un crecimiento exponencial de las imágenes en circulación. Lo que se había conocido como "fotografía después de la fotografía" tras el impacto de la tecnología digital (Batchen, 2002, Manovich, 1996, Ritchin, 2010), comienza ya a manifestarse como un auténtico paso más allá del sistema fotográfico en la medida que transforma tanto las pautas de su praxis como el mismo contenido de sus imágenes. O dicho en otros términos, la expansión de la imagen digital y su asociación con la web 2.0 a través del ordenador y los smartphones hace que el paradigma de la Cultura Kodak empiece a agrietarse (David, 2010). Cada vez se producen más imágenes y con más frecuencia, destinadas a ser compartidas fundamentalmente en las comunidades virtuales de las redes sociales posibilitando el acceso a su visualización por parte de cualquier persona en cualquier momento y desde cualquier lugar. ${ }^{3}$ Imágenes que, debido a su intrínseca 
maleabilidad, pueden además ser fácilmente alteradas, manipuladas o combinadas con otras imágenes $\mathrm{u}$ otros medios como texto y sonido dentro de archivos multimedia (Van House, 2011: 127-128). En un clima sociocultural abonado por las ideas de modificabilidad y conectividad, las interacciones sociales y las imágenes fotográficas quedan inextricablemente entrelazadas dentro de los sistemas tecnológicos digitales en red. Este escenario constituido por la conectividad y la interacción social está alterando las pautas que habían definido los usos y roles de las imágenes en la cultura fotográfica Kodak ${ }^{4}$ a la vez que deriva hacia una serie de fenómenos como el exceso de imágenes, la amateurización de la prácticas fotográficas y la mediación tecnológica de la memoria que suponen una profunda transformación de la funcionalidad tradicional de las imágenes fotográficas ya no sólo en el ámbito de la fotografía personal o amateur, sino también en los de la profesional y la artística.

\section{Exceso de imágenes y amateurización de las prácticas fotográficas}

En el actual panorama de convergencia de medios, la fotografía ha dejado de ser un medio autónomo. Las acciones que conforman la práctica común de la fotografía ya no quedan reducidas al uso de la cámara como dispositivo único y separado ni el acto de tomar fotografías es el momento central en la creación de significados de las imágenes fotográficas. Asistimos a lo que Daniel Rubinstein (2005: 8) ha llamado "era postcámara" donde la cámara fotográfica ha quedado absorbida en otros dispositivos como teléfonos móviles, tablets e incluso complementos de vestir como las Google Glass. Siguiendo esta línea, Sarah Kember (2012) señala cómo la fotografía se ha convertido en algo "ambiental" no sólo por la proliferación de imágenes que se esparcen sin restricción por dominios públicos y privados -ubicuidad como everywhere- sino también, y sobre todo, porque la fotografía es cada vez más inseparable de los logros e innovaciones asociadas con el fenómeno de la ubicuidad de los dispositivos informáticos, y de las mismas tecnologías de la comunicación, en casi todo tipo de objetos y dispositivos -ubicuidad como everyware o ubiquitous computing (Greenfield, 2006)-. Dicho en otros términos, en un entorno de convergencia medial, la fotografía ha traspasado el ámbito estricto de los llamados nuevos medios y de sus remediaciones (Bolter y Grussin, 1999), para implicarse con la racionalidad que subyace al sistema de la tecnociencia y la reordenación de la vida que tiene lugar bajo su amparo (Kember, 2012: 334).

Del "Apriete el botón" de Kodak hasta el "Qué esperas ¡toma fotos!" de Flickr, pasando por el "No pienses, dispara" de Sony, estos eslóganes publicitarios traslucen el fondo compulsivo que de manera creciente mueve a la praxis fotográfica desde sus inicios como tecnología de consumo así como la escasa actitud reflexiva que parece haber guiado a sus usuarios y que en el momento presente tendría su epítome en la compulsión por compartir imágenes en una suerte de networking without a cause, según la expresión de Geert Lovink (2011). Abundancia, saturación o exceso son algunos de los términos utilizados para describir con cierto espíritu crítico $-\mathrm{y}$ 
porque no decirlo, también pesimista- la situación actual de una iconosfera constituida sustancialmente por imágenes anodinas, repetitivas, mediocres o simplemente aburridas que apenas demandan atención ni requieren ningún análisis especial. Imágenes que conforman un "ambiente visual de fondo" como parte del "ruido blanco" generado en el seno de la cultura visual (Frosh, 2002; Batchen, 2008; Lister, 2011; Berger, 2011). Separadas de su contexto original las fotografias personales colgadas en internet parecen no tener autoría ni significado. Se presentan como inherentemente benignas e inofensivas, indiferentes e indiferenciadas, dispuestas a ser un versátil contenedor para albergar diferentes narrativas y discursos. Etiquetadas y enlazadas mediante hipervínculos, entre ellas refuerzan un sentido de identidad y unidad semánticas que les otorga el simple hecho de compartir similares metadatos (Rubinstein y Sluis, 2008: 23-24).

Los medios digitales han incrementado el volumen del flujo de imágenes hechas públicas pero a la vez, como es sabido, también han mejorado su calidad técnica y visual en comparación con las instantáneas realizadas con las cámaras analógicas de apuntar y disparar, gracias a la posibilidad de eliminar los resultados no deseados o esperados, y gracias al software para el proceso de imágenes incorporado en la misma cámara mediante un menú de opciones sencillas y automatizadas. Unas opciones que en el ordenador personal prácticamente ya no se distinguen de las del software profesional. La creciente accesibilidad a medios tecnológicos complejos, la capacidad de los usuarios para producir contenidos y difundirlos en el contexto de la web 2.0, ha impulsado una imparable proceso de amateurización de prácticas antes exclusivas de los mundos del arte, la fotografía profesional o el fotoperiodismo (Martín Prada, 2012: 39-41). Una cuestión que, a nuestro juicio central, aquí se abriría es si este proceso promueve una vía democrática para la innovación y la creatividad o si aboca a la expansión de la mediocridad que canibaliza y destruye la verdadera creatividad (Keen, 2007).

Paul Cobley y Nick Haeffner (2009) se han preguntado si esta accesibilidad tecnológica en el caso de las cámaras digitales favorece la alfabetidad visual (visual literacy) entre sus usuarios para señalar cómo la adquisición de una mayor competencia técnica en la fotografía amateur o doméstica no está de facto acompañada por una actitud reflexiva y crítica sobre las propias imágenes y las políticas de la representación que las rigen. Según el teórico de la fotografía Vilém Flusser (2001) la cámara fotográfica es un aparato programado y fotografiar de acuerdo con las virtualidades programadas produce fotografías "redundantes". Sólo cuando el fotógrafo busca las posibilidades no previstas dentro del programa de la cámara logra fotografías "informativas", fotografías que se oponen a los clichés puestos en juego por la cámara y que son fruto del espacio creado por la libertad humana frente al dictado de los aparatos. Se trata sin duda de una visión del fenómeno fotográfico que en buena medida podría se asumida como propuesta de acción para los actuales fotógrafos aficionados que cuelgan sus fotos en plataformas como Flickr, Instagram o Hipstamatic en le medida que el aparato ya no queda circunscrito a la cámara sino que engloba las funcionalidades previstas en estas mismas plataformas digitales. Así, en el momento 
que se producen catástrofes naturales, atentados o conflictos bélicos, los fotógrafos amateurs exponen sus imágenes documentales a través de las redes sociales, convirtiendo el acto de compartir imágenes en un proceso de compartir experiencias, con un significado muy distinto a como sucede con la inmensa mayoría de fotografías intrascendentes que inundan internet. En este sentido, nos parece interesante la idea propuesta por Daniel Palmer de una "experiencia participativa" de la fotografía en la que el usuario está conectado a la red y simultáneamente "luchando por visualizar el sentido de su posición fuera de ella" a través de sus experiencias. Aunque la misma fotografía participativa que llama a "resistir la lógica performativa del aparato conectado a la red" acaba abocando a una transferencia de las imágenes al complejo que conforma internet como gran repositorio icónico (Palmer, 2012: 43).

\section{Conectividad y memoria en red}

Desde la perspectiva de los estudios de tecnología, ciencia y sociedad se ha abordado la fotografía como un "sistema sociotécnico" en el que, a través de las prácticas llevadas a cabo por aficionados y usuarios de la fotografía, se ensamblan de modo dinámico elementos materiales y tecnológicos con otros discursivos y sociales (Gómez, 2012; Okabe e Ito, 2006; Van House, 2011). Se viene a incidir en la idea de que las fotografías en la era digital no se pueden separar de los usos, fines e intenciones que las personas realizan de las imágenes a través de las diferentes plataformas de la web 2.0 dirigidas a la subida y exhibición de imágenes. En este sentido, en un intento de sintetizar las prácticas emergentes, Nancy Van House (2011: 130-132) ha distinguido cuatro usos sociales de la fotografía personal: la memoria personal y de grupo, la creación y mantenimiento de las relaciones interpersonales, la autorrepresentación y, por último, la autoexpresión. Usos que no son en sí mismos novedosos pero que sí que han modificado la operatividad de la fotografía de un modo importante si tenemos en cuenta que se ha pasado de un uso fundamentalmente familiar a uno de carácter individual, del primado de la función como recuerdo al de la función comunicativa y de ser objeto de intercambio de recuerdos a servir de medio para el intercambio de experiencias (Van Dijck: 2007: 112-115). Así, el hecho de que las imágenes digitales estén prácticamente abocadas a ser compartidas a través de internet hace que éstas devengan cada vez más públicas - menos privadas- en su cometido de establecer vínculos personales y de articular la identidad social de los usuarios de redes sociales. De la misma manera, la memoria surgida de compartir experiencias a través de imágenes, lo que recordamos tanto a nivel individual como colectivo gracias a las fotografías, está cada vez más mediado por las prácticas sociotécnicas asociadas a la web 2.0 (Van House, 2008: 296).

Que las imágenes a través de la red sean cada vez más inmediatas y transitorias, puro reflejo de experiencias efímeras, se ha señalado en ocasiones como una amenaza para la memoria que descansaba en la materialidad y durabilidad de las fotografías analógicas. En Instagram o en Flickr el usuario no capta sino su vida cotidiana, 
ampliando indefinidamente el dominio de lo fotografiable hasta quedar indeterminado y disuelto en el universo de lo fugaz, lo mundano y banal. ${ }^{5}$ Como cada instantánea es rápidamente sustituida por otra en un flujo imparable de imágenes, la función documental de las imágenes sobre eventos pasados se antoja irrelevante (Champion, 2012; Rubinstein y Sluis, 2008). Son imágenes concebidas como reflejo de una "inmediatez vivencial" (Palmer, 2013: 186) y sometidas a una recepción igualmente urgente y desechable. El efecto comunicativo prima sobre el conmemorativo, lo transitorio se impone a lo durable. Mientras Roland Barthes (1990) planteaba que cada fotografia era una forma de "ça- $a$-été" que señalaba no sólo la historia del sujeto representado sino también su mortalidad, esta representación fotográfica "sin peso" de las imágenes en red sería una forma de "je-suis-là", un modo de decir "yo estoy aquí" que no haría referencia tanto a un pasado vivido como a la afirmación de un presente hueco (Simons, 2010: 572).

Sin embargo, la inmediatez vivencial y la imposición de lo comunicable en detrimento de lo permanente, no anula la memoria de entre los usos sociales de la fotografía aunque sí es cierto que adquiere un nuevo significado porque, como ha apuntado José Van Dijck, compartir experiencias a través de red siempre implica "un almacenamiento distribuido" (2008: 68). Al ser compartidas por internet las fotografías pueden permanecer en la red por tiempo indefinido, diseminadas e imposibles de mantener confinadas -y controladas- en un dominio personal, posibilitando que puedan aparecer en contextos imprevistos y ser apropiadas o redirigidas según otras intenciones distintas a las originales. Las instantáneas de la cárcel de Abu Ghraib son un ejemplo paradigmático de ello: fueron tomadas por soldados norteamericanos para su comunicación personal vía internet pero acabaron como prueba de cargo en los tribunales y como una dolorosa evidencia de la arrogancia militar en la "memoria cultural colectiva" de América. "La memoria en imágenes, concluye la profesora holandesa, queda incrustada en los sistemas en red, por siempre dispersa, perpetuamente almacenada en el infinito laberinto de [su] vida virtual" (Van Dijck, 2008: 70). Como ejemplo paralelo pero de consecuencias bien distintas, tenemos el caso de Stacy Snyder, una madre soltera de 25 años de edad que en 2006 había completado sus estudios aspiraba a ser profesora, sin embargo la universidad le denegó su certificado porque había tenido en el pasado un comportamiento inadecuado e impropio de una profesora ¿Qué ocurrió? La administración de la universidad había encontrado en internet una fotografía que ella misma colgó años atrás en MySpace, disfrazada de pirata bebiendo de un vaso de plástico y con el pie de foto que decía "Pirata Borracha". A partir de este caso Viktor Mayer-Schönberger ha llevado a cabo un análisis de las luces y, sobre todo, de las sombras de esta persistencia de la memoria distribuida señalando cómo uno de los cambios fundamentales de la tecnología digital ha sido precisamente la inversión del equilibrio entre recordar y olvidar consustancial a la mente humana: ahora, por defecto, toda la información queda rendida a la memoria digital, mientras que olvidar es más bien la excepción. Internet siempre recuerda lo que Stacy o cualquiera de nosotros puede querer olvidar. La consecuencia de este hecho es una sociedad de la vigilancia -en un sentido temporal del panóptico de Bentham- que puede convertir cualquier acontecimiento de nuestro pasado -hasta 
el más insignificante- en una amenaza constante para el presente o para nuestras expectativas de futuro (2009: 196).

A este respecto, queremos añadir dos cuestiones para la reflexión. Por un lado, el hecho de que la autorrepresentación identitaria de los individuos en las redes sociales como Fotolog o Flickr, se articula mediante la adopción -sobre todo por parte de adolescentes- de estereotipos de género y erotismo tomados de la publicidad (Tortajada, Araüna y Martínez, 2013) que pueden reforzar lecturas de dichas imágenes asimismo estereotipadas y, con ello, desvirtuar sus intenciones originales. Y por otro, que esta pérdida de control sobre la imagen personal en contextos no previstos tiene lugar, paradójicamente, con la tecnología digital cuya versatilidad que capacita al individuo para poder dar la forma deseada a su identidad en la autorrepresentación fotográfica, tal vez en el ejercicio de una libertad que, a la postre, es más ilusoria que efectiva.

En los dos casos expuestos el acto de compartir ha sido consciente e intencionado pero no se tiene conciencia de lo que ocurre después con las imágenes e informaciones que, como en una pesadilla, pueden emerger de manera inadvertida. Una vez que las fotografías ingresan en la red, los metadatos del perfil del usuario fijados en los archivos (qué prefiere, con quien se relaciona, con qué propósitos..) se convierten en habitantes de la memoria de internet. Metadatos que serán objeto de relación e interpretación mediante los algoritmos de los motores de búsqueda, una auténtica caja negra fuera del control de los usuarios y que Andrew Hoskins ha llamado reveladoramente "inconsciente tecnológico" (2009: 96). La construcción de nuestro comportamiento social en internet se halla, en el fondo, determinada por este "inconsciente tecnológico" no menos de lo que lo está por el inconsciente psicológico en la vida real. Idea que ha servido para que José Van Dijck precise que esta memoria en red no se constituiría tanto como el registro de una "memoria colectiva" sino como una "memoria conectiva" que "construye activamente conexiones entre perspectivas, experiencias y recuerdos" (2010: 402) sobre la base de los metadatos enlazados por la red, de una manera menos rígida -consciente-, más modulable y abierta -inconsciente-, que la estructura de archivo propia de una memoria colectiva.

\section{Conclusiones abiertas}

Sobre la idea de que las interacciones sociales y las imágenes fotográficas están inseparablemente entrelazados dentro de las plataformas tecnológicas de las redes sociales, hemos enfocado la ubicuidad de dispositivos e imágenes, la convergencia de medios y la conectividad como claves del nuevo escenario que se abre para la fotografía. Como conclusión queremos poner de manifiesto algunas cuestiones candentes sobre el rol de las imágenes en el mundo contemporáneo y las implicaciones que de ellas se derivan en relación fundamentalmente con el exceso de imágenes y la memoria en red. 
Los efectos del exceso de imágenes sobre nuestro entorno sociocultural han conducido a plantear la necesidad una "ecología de las imágenes" (Sontag, 2006: 251) que propicie, más que un expurgo, que las imágenes recuperen su función epistemológica, expresiva o emocional, eclipsadas por la sobreabundancia. Incluso, en este contexto de extrema saturación icónica, sería interesante una estrategia de "reciclaje de imágenes" que fomente la posibilidad de reapropiar y reasociar imágenes con el fin de crear nuevas colecciones, secuencias y yuxtaposiciones y, por tanto, nuevos significados. En vez de -solamente- "producir" fotografías se debería pensar también en "prescribir" otros sentidos a las existentes (Fontcuberta: 2011). Surge así la necesidad de una pedagogía sobre las imágenes que replantee y reconduzca la mediación entre producir y consumir imágenes, que empape de sentido crítico conceptos como creación, lectura y recepción de las imágenes pero también que desarrolle una conciencia atenta a las estructuras de producción, gestión y difusión de imágenes en la web 2.0, pero también a sus condicionamientos legales y económicos ¿Hacia donde apuntar esta responsabilidad? ¿Hacia el sistema educativo? ¿Hacia la resistencia encabezada por ciertas prácticas artísticas como "anticipación poética" de una "forma más creativa, consciente y sensible de habitar la red" (Martín Prada, 2102: 47)? ¿O hacia una conciencia individual que se acerque a los asuntos de la vida diaria con la convicción de que lo personal también es político?

Por último, la memoria ha dejado de ser radicalmente un factor exclusivamente humano para quedar mediatizada tecnológicamente por las redes sociales y sus plataformas digitales. La creencia utópica en la infalibilidad de la memoria de la máquina, en contraste con la memoria humana falible y caprichosa, ha encontrado su inesperado contrapunto en el "inconsciente tecnológico", poniendo en evidencia problemas intrínsecos a la funcionalidad de la memoria en red en tanto que memoria que no olvida. El reverso de esta aparente solidez de la memoria es precisamente la fragilidad de los recursos digitales en la medida que su operatividad depende "un complejo de decisiones técnicas, institucionales y políticas que determinan la naturaleza de nuestros archivos" ¿En qué manos dejamos nuestros archivos de datos? Es crucial tener presente esta cuestión pues la necesaria articulación del recuerdo y el olvido de dichos materiales es la que nos brindará la oportunidad de "reconstruirnos a nosotros mismos", ya sea por razones nostálgicas o utilitarias (Van House y Churchill, 2008: 296 y 307), como individuos y también como sociedad.

\section{Bibliografía}

BARTHES, R. (1990). La cámara lúcida. Nota sobre la fotografía [1980]. Barcelona: Paidós.

BATCHEN, G. (2008). "Snapshots. Art History and the Ethnographic Turn". En Photographies, vol. 1, $\mathrm{n}^{\mathrm{o}} 2$ 2. p. 121-142.

BATCHEN, G. (2002). Each Wild Idea. Writing, Photography, History. Cambridge MA/Londres: MIT Press. 
BERGER, L. (2009). "The Authentic Amateur and the Democracy of Collecting Photographs". En Photography \& Culture, vol. 2, n 1. p. 31-50.

(2011). "Snapshots, or Visual Culture's Clichés". En Photographies, vol. 4, nº 2. p. 175-190.

BOLTER, D. J. y GRUSIN, R. (1999). Remediation. Understanding New Media. Cambridge MA/Londres: MIT Press.

CHALFEN, R. (1987). Snapshot Versions of Life, Bowling Green: Bowling Green State University Popular Press.

CHAMPION, Ch. (2012). "Instagram: je-suis-là". En Philosophy of Photography, vol. $3, n^{\circ} 1$. p. 83-88.

COBLEY, P. y HAEFFNER, N. (2009). "Digital Cameras and Domestic Photography: Communication, Agency and Structure". En Visual Commnunication, vol. 8, $\mathrm{n}^{\mathrm{o}} 2$. p. $123-146$.

DAVID, G. (2010). "Camera Phone Images, Videos and Live Streaming: A Contemporary Visual Trend". En Visual Studies, vol. 25, no 1. p. 89-98.

FLUSSER, V. (2001). Una filosofia de la fotografía [1984]. Madrid: Síntesis.

FONTCUBERTA, J. (2011). "Por un manifiesto postfotográfico" en Suplemento Cultura/s de La Vanguardia, 11-05-2011. http:/www.lavanguardia.com/ cultura/20110511/54152218372/por-un-manifiesto-posfotografico.html [02-102013]

GÓMEZ, E. (2012). De la cultura Kodak a la imagen en red. Barcelona: UOCpress. GREENFIELD, A. (2006). Everyware. The Dawning Age of Ubiquotous Computing. Berkeley: New Readers.

KEEN, A. (2007). The Cult of the Amateur: How Today's Internet is Killing Our Culture. Nueva York: Doubleday.

KEMBER, S. (2012). "Ubiquitous Photography". En Philosophy of Photography, vol. $3, n^{\circ}$ 2. p. 331-348.

LISTER, M. (2011). “¿Demasiadas fotografías? La fotografía como contenido generado por el usuario". En Adcomunica. Revista cientifica de estrategias, tendencias e innovación en comunicación, $\mathrm{n}^{\circ}$ 2. p. 25-41.

(comp.) (1997). La imagen fotográfica en la cultura digital. Barcelona: Paidós. et al. (2006). New Media: A Critical Introduction. Abingdon/Nueva York: Routledge.

LOVINK, G. (2011). Networks Without a Cause. A Critique of Social Media. Cambiridge: Plity Press.

MANOVICH, L. (1996). “The paradoxes of Digital Photography”. En AMELUNXEN, H. V. et al. (eds.): Photography After Photography. Memory and Representation in the Digital Age. Munich: G+B Arts. p. 57-65.

MARTÍN PRADA, J. (2012). Prácticas artisticas e internet en la época de las redes sociales. Madrid: Akal.

MAYER-SCHÖNBERGER, V. (2009). Delete. The Virtue o Forgetting in the Digital Age, Princenton/Oxford: Princenton University Press.

MILLER, D. A. y EDWARDS, W. K. (2007). "Give and Take: A Study of Consumer Photo-Sharing Culture and Practice". En ROSSON, M. B. y GILMORE, D. 
Proceedings of the SIGCHI Conference on Human Factors in Computing Systems, Nueva York: ACM. p. 347-356.

MUNIR, K. A. Y PHILLIPS, N. (2013). "El nacimiento del momento Kodak" [2005]. En VICENTE, P. (ed.). Álbum de familia, [re]presentación, [re]creación e [in] materialidad de las fotografías familiares, Madrid: La Oficina de Arte y Ediciones. p. 33-40.

MURRAY, S. (2008). "Digital Images, Photo-Sharing, and Our Shifting Notions of Everyday Aesthetics". En Journal of Visual Culture, vol. 7, nº 2. p. 147-163.

OKABE, D. e ITO, M. (2006). "Everyday Contexts of Camera Phone Use: Steps toward Techno-Social Frameworks". En HÖLFLICH, J. y HARTMANN, M. (eds.). Mobile Communication in Everyday Life: Ethnographicc Views. Observations and Reflections. Berlín: Frank \& Time. p. 79-102.

PALMER, D. (2012). "Redundacy in Photography". En Philosophy of Photography, vol. $3, n^{\circ} 1$. p. $36-44$.

(2013). "Archivos emocionales: el intercambio de fotos online y el cultivo del yo" [2010]. En VICENTE, P. (ed.). Álbum de familia, [re]presentación, [re]creación e [in]materialidad de las fotografías familiares, Madrid: La Oficina de Arte y Ediciones. p. 183-195.

RITCHIN, F. (2010). Después de la fotografía. México: Océano.

RUBINSTEIN, D. (2005). "Cameraphone Photography: the Death of the Camera and the Arrival of Visible Speech". En The Issues in Contemporary Culture and Aesthetics, $\mathrm{n}^{\mathrm{o}}$ 1. p. 113-118.

RUBINSTEIN, D. y SLUIS, K. (2008): “A Life More Photographic”. En Photographies, vol. $1, \mathrm{n}^{\circ}$ 1. p. 9-28.

SIMONS, J. (2010). "Weightless photography". En SWINNEN, J. y DENEULIN, L. (eds.). The Weight of Photography: Photography History Theory an Criticism. Introductory Readings. Bruselas: ASP Press. p. 557-577.

SLATER, D. (1991). "Consuming Kodak". En SPENCE, J y HOLLAND, P. (eds.). Family Sanps. The Meaning of Domestic Photography. Londres: Virago. p. 49-59. (1997). "La fotografía doméstica y la cultura digital". En LISTER, Martin (comp.). La imagen fotográfica en la cultura digital. Barcelona: Paidós. p. 173-195.

SONTAG, S. (2006). Sobre la fotografia [1977]. México: Alfaguara.

TORTAJADA, I.; ARAÜNA, N. y MARTÍNEZ, I. (2013). "Estereotipos publicitarios y representaciones de género en las redes sociales". En Comunicar. Revista Cientifica de Educomunicación, no 41, v. XXI. p. 177-186.

VAN DIJCK, J. (2007). Mediated Memories in the Digital Age. Standford CA: Standford University Press.

(2008). "Digital Photography: Communication, Identity, Memory". En Visual Commnunication, vol. 7, $\mathrm{n}^{\circ}$ 1. p. 57-76.

(2010). "Flickr and the culture of connectivity: Sharing views, experiencies, memories". En Memory Studies, vol. 4, nº 4. p. 401-415.

VAN HOUSE, N. (2011). "Personal Photography, Digital Technologies and the Uses of the Visual". En Visual Studies, vol. 26, nº 2. p. 125-134. 
VAN HOUSE, N. y CHURCHILL, E. (2008). “Techonolgies of memory: Key issues and critical perspectives”. En Memory Studies, vol. 1, n 3. p. 295-310.

\section{Notas}

1 Como antropólogo, Chalfen insistía en el concepto de cultura fotográfica para referirse a aquellas ideas, valores y conocimientos que uno tiene que aprender, conocer o aplicar en orden a participar apropiadamente en el "modo doméstico de comunicación fotográfica", ya sea como fotógrafo y/o como perceptor de fotografías.

2 Según Canalys Research en 2011 se vendieron en total 487,7 millones de smartphones, un 63 \% más sobre los 299,7 millones vendidos en 2010. El mercado global de ordenadores personales (portátiles, sobremesa y tablets) creció un 15\% en 2011 hasta los 414,5 millones de unidades vendidas, de manera que, por primera vez, el volumen de ventas de smartphone supera al de los ordenadores personales, tendencia que se ha mantenido en 2012. http://www.canalys.com/newsroom/smart-phones-overtake-client-pcs-2011 http://www.canalys.com/newsroom/mobile-device-market-reach-26billion-units-2016 [02-09-2013].

3 Según el informe Focus on Efficiency de 16 de septiembre de 2013, elaborado por Internet.org, Facebook se ha convertido en el mayor sitio de internet para compartir imágenes con una media diaria de 350 millones de imágenes subidas, superando a Flickr que cada día incorpora 3,5 millones de nuevas fotografías. Como resultado las imágenes representan la mayor fuente de datos usados en Facebook. https://fbcdn-dragon-a.akamaihd.net/hphotos-ak-prn1/851575_520797877991079_393255490_n. pdf [07-10-2013].

4 Miller y Edwards (2007) han mostrado, sin embargo, cómo junto a la comunidad de practicantes de la fotografía en conexión con las redes sociales -los llamados sanprs-convive una Cultura Kodak adaptada a la tecnología digital cuyos participantes, usuarios de cámaras digitales y de internet, mantienen un concepto de la fotografía en continuidad con los códigos de aquella y el "modo doméstico" y conmemorativo de la fotografía.

5 Susan Murray (2008:155-156) refiere una "estética cotidiana" que, entre la plétora de imágenes de internet, muestran algunas fotografías cuando exploran la belleza de lo mundano, de lo kitsch o de los entornos urbanos en decadencia.

\section{El autor}

Enric Mira Pastor. Doctor en Filosofía y CC. de la Educación por la Universidad de Valencia y Profesor Titular de la Universidad de Alicante en el Departamento de Comunicación y Psicología Social. Es miembro de la Asociación Internacional de Críticos de Arte. En 1994 recibió el VI Premi Espais de la Crítica d'Art. Ha publicado los libros La vanguardia fotográfica de los años setenta en España (1991), Alcalácanales. El lenguaje artístico de la electrografía (2000) y Ana Teresa Ortega. Foto-esculturas e instalaciones (2006). Ha escrito artículos sobre teoría e historia de la fotografía para diferentes medios especializados como Cimal, Lápiz y Photovision, así como textos de catálogos para exposiciones tanto individuales como colectivas de autores españoles Asimismo ha escrito capítulos en los libros Mercancía y espectá- 
culo: una perspectiva teórica sobre las artes plásticas como industria cultural (2009), Instantáneas de la teoría de la fotografía (2009), La polémica sobre la cultura de masas. Una antología crítica en el periodo de entreguerras (2012) y Metodologías comparatistas y literatura comparada (2012). 